\title{
OS DISCURSOS LACANIANOS COMO LAÇOS SOCIAIS
}

\section{Lacanian Discourses as Social Bonds}

\section{Los Discursos Lacaniano como Lazos Sociales}

\section{Les Discours Lacaniens comme Liens Sociaux}

DOI: $10.5020 / 23590777 . r s . v 18 i E s p .6562$

\section{Luis Flávio Silva Couto (Lattes)}

Professor adjunto da Pontifícia Universidade Católica de Minas Gerais atuando na graduação em Psicologia, bem como no Programa de Pós-graduação estrito senso (Mestrado e Doutorado) em Psicologia da PUC Minas.

\section{Jônatas Lança de Queiroz Casséte (Lattes)}

Mestrando em Psicologia pela Pontifícia Universidade Católica de Minas Gerais (2016-2018). Possui graduação em Psicologia pela Pontifícia Universidade Católica de Minas Gerais (2014).

\section{Fernando Hartmann (Lattes)}

Professor da Universidade Federal de Rio Grande (FURG), Pós doutorado em Psicanálise pela Universidade de Paris Diderot (Paris 7), Analista Membro da Association Lacanienne Internationale (ALI), Membro da Associação Psicanalitica de Porto Alegre (APPOA)

\section{Marcelo Fonseca Gomes de Souza (Lattes)}

Doutor em Psicologia. Professor do curso de Psicologia da Faculdade Divinópolis (FACED), de Pedagogia da Faculdade de Educação (FaE) da Universidade do Estado de Minas Gerais (UEMG) e Professor substituto do Departamento de Psicologia da UFMG.

\section{Resumo}

Este artigo é uma revisão teórica que aborda a produção da teoria lacaniana dos discursos como laços sociais e suas implicações na compreensão do inconsciente. Partimos da concepção lacaniana de que o inconsciente é estruturado como uma linguagem e das implicações teóricas da lógica estruturalista, indicando que as estruturas de linguagem precedem o sujeito e as possibilidades de laço social. Tomamos o Seminário XVII como ponto de partida, levando em conta o contexto histórico de sua transmissão. Apresentamos a ideia lacaniana de que o campo da linguagem é o que baliza a relação do sujeito com o outro, mas que, nessa relação, algo fracassa, possibilitando o surgimento do sujeito a partir da perda de um objeto. Desse lugar, toma forma o objeto a, o objeto para sempre perdido na operação de constituição do sujeito, que implica na alienação e no endereçamento ao Outro. Apresentamos a estrutura dos discursos, os elementos que os compõe, seus lugares e, por fim, a lógica presente em cada um dos quatro discursos (mestre, histérica, universitário e analista) chamados por Lacan de radicais. O que a teoria dos discursos nos ensina é que a articulação significante produz a amarração social, ao mesmo tempo em que, como efeito de seu tropeço, nos apresenta o sujeito do inconsciente.

Palavras-chave: laços sociais; inconsciente; linguagem; objeto a.

\section{Abstract}

This article is a theoretical review that deals with the production of the Lacanian theory of discourses as social bonds and their implications in understanding the unconscious. We start from the Lacanian conception that the unconscious is structured as a language and from the theoretical implications of structuralist logic, indicating that language structures precede the subject and the possibilities of social bond. We take XVII Seminar as a starting point, taking into account the historical context of its transmission. We present the Lacanian idea that 
the field of language is what marks the relation of the subject to the other, but that in this relation something fails, enabling the subject to arise from the loss of an object. From this place, the object a takes shape, the object forever lost in the operation of constitution of the subject, which implies the alienation and the addressing to the Other. We present the structure of the discourses, the elements that compose them, their places and, finally, the logic present in each of the four discourses (master, hysteric, university and analyst) called by Lacan of radicals. What the theory of discourses teaches us is that the significant articulation produces the social bonding, at the same time as, as an effect of its stumbling, it presents the subject of the unconscious.

Keywords: social bonds; unconscious; language; object a.

\section{Resumen}

Este artículo es una revisión teórica que trata de la producción de la teoría lacaniana de los discursos como lazos sociales y sus implicaciones en la comprensión del inconsciente. Partimos de la concepción lacaniana de que el inconsciente es estructurado como un lenguaje y de las implicaciones teóricas de la lógica estructuralista, indicando que las estructuras del lenguaje preceden el sujeto y las posibilidades de lazo social. Tomamos el Seminario XVII como punto de partida, llevando en cuenta el contexto histórico de su transmisión. Presentamos la idea lacaniana de que el campo del lenguaje es lo que baliza la relación con el otro, pero que, en esta relación, algo fracasa, posibilitando el surgimiento del sujeto a partir de la pérdida de un objeto. De este lugar, toma forma el objeto a, el objeto para siempre perdido en la operación de la constitución del sujeto, que implica en la alienación y en el direccionamiento al Otro. Presentamos la estructura de los discursos, los elementos que se los componen, sus lugares y, por fin, la lógica presente en cada uno de los cuatro discursos (maestro, histérica, universitario y analista) llamados por Lacan de radicales. La teoría de los discursos nos enseña es que la articulación significante produce el amarre social, a la vez que, como efecto de su tropiezo, nos presenta el sujeto del inconsciente.

Palabras clave: lazos sociales; inconsciente; lenguaje; objeto a.

\section{Résumé}

Cet article est une revue théorique qui traite de la production de la théorie lacanienne du discours comme des liens sociaux et ses implications dans compréhension de l'inconscient. On prend la conception lacanienne où l'inconscient est structuré comme un langage. On prend aussi les implications théoriques de la logique structuraliste, cela indique que les structures de la langue précèdent le sujet et les possibilités de liaison sociale. Le 17ème Séminaire est le point de départ, en faisant attention au contexte historique de sa transmission. On présente l'idée lacanienne sur laquelle le champ du langage est l'élément qui limite le rapport du sujet avec l'autre, mais dans cette relation, quelque chose échoue, ce qui rend possible la naissance du sujet à partir de la perte d'un objet. C'est là où l'objet prend forme. L'objet pour toujours perdu dans la constitution du sujet, ce qui implique l'aliénation et l'adresse à l'autre. On présente la structure des discours, les éléments qui les composent, leurs places et, finalement, la logique présente dans chacune des quatre discours (maître, hystérique, universitaire et analyste) appelés radicaux par Lacan. Ce que la théorie des discours nous enseigne est que l'articulation significative produit un détachement social, au même temps qu'elle nous présente le sujet de l'inconscient comme l'effet de son trébuché

Mots clés: des liens sociaux; inconscient; langue; objet a.

O presente trabalho tem como objetivo nuclear propor uma revisão teórica sobre a teoria lacaniana dos discursos a partir do seu desenvolvimento ao longo de O Seminário livro 17: o avesso da psicanálise. Utilizamos como estratégia metodológica uma lógica de articulação da exposição que obedeceu à seguinte ordem: (a) uma apresentação da teoria dos discursos articulada em torno da coexistência de dois diferentes tipos de recursos: a teoria estruturalista da linguagem e a teoria do objeto $a$; (b) uma localização do contexto histórico desse seminário e das principais problemáticas que ele visa responder; (c) uma desmontagem da estrutura discursiva, visando apresentar conceitualmente seus quatro elementos, seus lugares topológicos e sua lógica de circulação; e (d) uma exposição sintética do que cada discurso representa.

Antes, contudo, de percorrer a trajetória proposta, é preciso, uma vez que a teoria dos discursos é o tema central deste trabalho, perguntarmo-nos como Lacan o define [o discurso]. Já na primeira lição da referida obra, ele mesmo explicita como devemos compreendê-lo: 
Ocorreu-me com muita insistência no ano passado distinguir o que está em questão no discurso como uma estrutura necessária, que ultrapassa em muito a palavra, sempre mais ou menos ocasional. O que prefiro, disse, e até proclamei um dia, é um discurso sem palavras.

É que sem palavras, na verdade, ele pode muito bem subsistir. Subsiste em certas relações fundamentais. Estas, literalmente, não poderiam se manter sem a linguagem. Mediante o instrumento da linguagem instaura-se um certo número de relações estáveis, no interior das quais certamente pode inscrever-se algo bem mais amplo, que vai bem mais longe do que as enunciações efetivas (Lacan, 1969-1970/1992, p. 11-12).

O discurso é uma estrutura que se encontra fundada na própria lógica de funcionamento da linguagem e de seus efeitos sobre a realidade. Está, ademais, organizado de tal modo que tem, como consequência, o estabelecimento de formas históricas de vínculo social. Dessa maneira, o discurso não é concebido como uma "realidade primeira a ser interpretada em seu sentido", mas é o efeito da combinatória significante sobre o mundo (Rabinovich, 2001, p.2). Isso significa que nele há uma prevalência e uma anterioridade dos lugares e das suas regras de articulação sobre os destinos dos modos de enlaçamento entre os seres falantes [parlêtres].

Se é verdade, por um lado, que o discurso é sem palavras, também é verdade, por outro lado, que ele é a condição de possibilidade para a proliferação de palavras e de sentidos. Queremos afirmar com isso que, assim como na teoria estruturalista, na qual o sentido não deve ser pensado como um dado a priori, mas deve ser considerado como o efeito do jogo de permutas das posições dos elementos na estrutura, surgindo sempre em excesso e em demasia (Deleuze, 1974), assim também a teoria dos discursos é, entre os comentadores de Lacan, objeto de acentos diferentes e de interpretações plurais. Dela extraíram-se, ao longo do tempo, explicações diversas, tais como: (i) seu uso como um rico operador conceitual que permite um contraste epistemológico entre a teoria psicanalítica, a teoria da ciência e a filosofia; (ii) seu emprego como um importante recurso heurístico para interpretar as formas prevalentes de enlaçamento social ao longo da história do Ocidente; (iii) sua utilização como uma potência crítica para apontar os embaraços, os entraves e os labirintos da sociedade contemporânea, sobretudo para denunciar as formas deploráveis assumidas pelo capitalismo atual e (iv) sua aplicação como recurso para se pensar o diagnóstico e a direção do tratamento em uma análise.

Em que pese a relevância dessas diferentes interpretações, nosso objetivo, neste trabalho, não é o de confrontar a posição que assumimos neste texto com aqueles usos distintos que os comentadores fazem da teoria lacaniana dos discursos. Visamos apenas revisar a teoria explicando a distribuição dos elementos em cada um dos quatro discursos - do mestre, da histérica, do analista e do universitário - e compreendê-los como formas específicas de enlaçamento social, destacando o ponto de impossibilidade em torno do qual cada um deles gravita.

\section{A Estrutura dos Discursos: A Via Estruturalista e a Inserção do Objeto a}

Acima, apresentamos o conceito lacaniano de discurso definindo-o enquanto laço social, como um discurso sem palavras, em que subsistem certas relações fundamentais e estáveis entre seus elementos. A fórmula inicial da qual Lacan se serviu para introduzir essa teoria é a mesma que ele já havia utilizado, na década de 1950, para a construção de seu programa de retorno a Freud. Trata-se da célebre conceituação do significante, a saber: "o significante é o que representa o sujeito para outro significante".

Há estrutura - não poderíamos designá-las de outro modo - para caracterizar o que se pode extrair daquele em forma de sobre o qual me permiti, ano passado, enfatizar um emprego particular - quer dizer, o que se passa em virtude da relação fundamental, aquela que defini como sendo a de um significante com outro significante. Donde resulta a emergência disso que chamamos sujeito - em virtude do significante que, no caso, funciona como representando esse sujeito junto a um outro significante (Lacan, 1969-1970/1992, p. 11).

A teoria do significante em Lacan está apoiada na antropologia de Lévi-Strauss e na linguística de Jakobson. A estrutura, composta pela combinatória dos significantes, não é pensada apenas como o que antecede a existência do sujeito, mas aquilo que se institui como a própria condição de possibilidade para o seu advento. $\mathrm{O}$ estruturalismo lacaniano, que permite a formalização do inconsciente freudiano e a localização do sujeito que concerne à experiência da psicanálise, pode ser reduzido a essa pequena fórmula:




O sujeito do inconsciente (\$), conforme a notação expõe, é pensado como um efeito da cadeia significante, e o seu desejo é caracteristicamente compreendido como desejo do desejo do Outro. O Outro (A), aqui, não é concebido de outro modo a não ser como um lugar que comporta o vasto conjunto dos significantes da língua.

A teoria dos discursos, todavia, abriga um elemento adicional, que demarca uma ruptura com o viés estruturalista. $\mathrm{Na}$ operação de constituição do sujeito, que se dá por meio da interferência do significante paterno sobre o gozo da mãe, vê-se surgir um resto heterogêneo ao plano simbólico. Esse resto, que Lacan já havia introduzido no seminário anterior a partir da homologia com o conceito marxista de mais-valia, é nomeado como objeto $a$. Trata-se de um resto real. Ele revela que a estrutura não deve ser reduzida à dimensão simbólica, uma vez que comporta esse elemento êxtimo.

Lacan, em O Seminário livro 17, dá um passo para além do Édipo freudiano. Seu argumento se encaminha de tal maneira que, na lição VIII, ele acaba por propor uma superação do mito edipiano por meio da formalização da estrutura. O complexo de Édipo é, então, retirado do lugar de fundamento transcendental da lei simbólica para ser concebido apenas como uma narrativa mítica, que reveste, com uma forma trágica, uma perda que é introduzida pela própria existência da linguagem. O objeto fálico sucumbe a um destino semelhante, visto que ele se torna apenas um recurso [do neurótico] utilizado para encobrir o resíduo real engendrado pela operação do seu advento no campo do Outro (Souza, 2015).

Duas consequências podem ser extraídas dessa reorientação teórica: (i) por um lado, o Nome-do-Pai deixa de ser pensado como o significante universal que impõe a lei da proibição do incesto, garantindo a interdição do acesso da criança ao gozo do objeto materno, para ser pensado no plural [os nomes do pai], ou seja, como semblantes dos quais os sujeitos se servem para encobrir a impossibilidade estrutural engendrada pelo ato de sua inserção no domínio da lei simbólica ${ }^{1}$; (ii) por outro lado, a perda de gozo passa a ter anterioridade sobre a proibição do incesto, ou seja, a inacessibilidade ao gozo é muito mais um efeito da própria existência da estrutura da linguagem no real do que uma consequência produzida pela proibição do acesso ao objeto incestuoso [tabu do incesto]. A estrutura simbólica, articulada a partir da teoria dos discursos, passa, portanto, a dar voltas em torno de um ponto de impossibilidade real. Esta impossibilidade, ligada à perda de gozo irrecuperável, é sintetizada pela noção de objeto $a$ (Souza, 2015).

A partir da operação descrita, chegamos ao matema abaixo, no qual estão representados quatro elementos, distribuídos em quatro lugares diferentes. Eles compõem a matriz a partir da qual todos os quatro discursos serão produzidos.

$$
\frac{S 1}{\$} \rightarrow \frac{S 2}{a}
$$

Tal matriz, que articulamos ao próprio instante do advento do sujeito em um mundo simbolicamente estruturado advento que não se faz sem uma perda elementar de gozo -, é nomeada por Lacan de discurso do inconsciente, e é homóloga ao discurso do mestre ${ }^{2}$. Uma vez definida essa composição básica, formada por quatro letras e quatro lugares, cuja ordem não poderá mais ser embaralhada ( $\mathrm{S} 1 \rightarrow \mathrm{S} 2 \rightarrow \mathrm{a} \rightarrow$ \$), bastará operar por rotações sucessivas de um quarto de giro, isto é, rotações de $60^{\circ}$, para que as outras três estruturas discursivas também surjam. Donde temos:

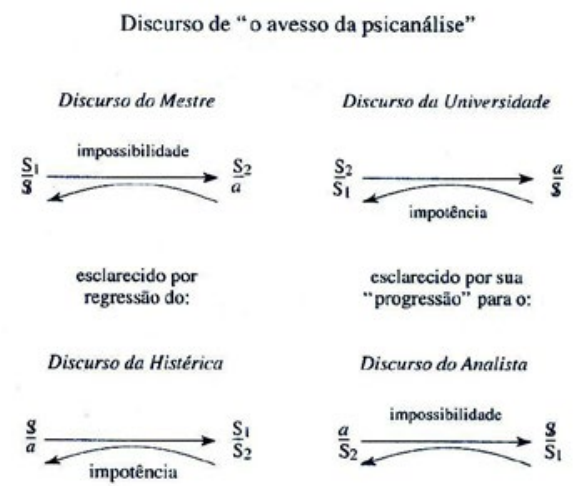

Fonte: Radiofonia (Lacan, 1970/2003, p. 447).

\footnotetext{
1 Esta impossibilidade estrutural é concernente, como Lacan não cessará de repetir, à impossibilidade da relação complementar entre os sexos. 2 "Por mais besta que seja esse discurso do inconsciente, ele corresponde a algo relativo à instituição do próprio discurso do mestre. É isso que se chama inconsciente. Ele se impõe à ciência como um fato (Lacan, 1969-70/1992)".
} 
Esse aparelho, conforme diz Lacan, não é abstraído da realidade. É ele, ao contrário, que "está desde já inscrito naquilo que funciona como essa realidade", a saber: "a do discurso que já está no mundo e o sustenta" (Lacan, 1969-1970/1992, p. 13).

Para nomear cada um dos discursos, Lacan se lembrará das três profissões impossíveis demarcadas por Freud: a de governar [Regieren], a de ensinar [Erziehen] e a de analisar [Analysieren]. A elas, acrescentará uma quarta: a de "fazer desejar". Teremos, assim, respectivamente, a composição de cada um dos quatro discursos, a saber: o do mestre, o do universitário, o do analista e o da histérica.

\section{Notas sobre o Contexto Histórico de O Seminário livro 17: O Avesso da Psicanálise}

O avesso da psicanálise foi um seminário proferido em meio a um período de intensa turbulência no domínio universitário francês. A memória do movimento de maio de 1968 ainda estava fresca e ressoava entre boa parte dos estudantes. De um modo geral, dentre os principais temas de contestação do período, destacavam-se:

a recusa do caráter classista da universidade; a denúncia da falsa neutralidade e da falsa objetividade do saber; a denúncia da parcelização e tecnocratização do saber; a contestação dos cursos ex-cathedra; a denúncia dos professores conservadores ligados à política de governo; o questionamento do lugar que, na divisão capitalista do trabalho, os diplomados iriam ocupar; a denúncia da escassez de possibilidade de empregos qualificados (Thiollent, 1998, p. 70).

Além dessas críticas às formas assumidas pela ciência dentro do ensino universitário, da desigualdade social gerada pelos avanços do sistema capitalista cada vez mais globalizado e do pouco engajamento dos professores nos processos de mudança social, os estudantes também questionavam os hábitos e os costumes legados pela tradição. O lema "é proibido proibir" tornou-se uma das principais bandeiras do Movimento. O que, portanto, estava em questão era uma crítica às instituições e às formas assumidas pelo poder, dentre elas, é claro, ao próprio modo de constituição e transmissão do saber.

O ensino de Lacan não se manteve isento aos ataques estudantis. Lacan foi acusado de adotar uma posição política conservadora e também de aproximar a psicanálise do formalismo assumido pelo discurso da ciência ${ }^{3}$. Em que pese a razão e/ou a desrazão por trás desses ataques, certamente ele não se manteve imune a eles. Se, por um lado, Lacan se mostrou acidamente crítico em relação ao que causava e ao que se podia esperar da revolução ${ }^{4}$; por outro lado, contudo, propôs um Seminário, o décimo sexto, intitulado De um Outro ao outro (Lacan, 1968-1969/2008), no qual incorporaria à psicanálise parte da teoria marxista e produziria uma passagem do primado da lei simbólica (A) para o primado do objeto (a), revelando, por meio dela, a sua atenção para os acontecimentos nada triviais do seu tempo.

As novas formas de manifestação e tratamento dos sintomas, mudanças na configuração da família tradicional (com o respectivo declínio social da função paterna), novas maneiras de relação estabelecidas no mundo do trabalho, bem como a reconfiguração das formas de produção e circulação das mercadorias no capitalismo global e de consumo não passaram despercebidos por Lacan (Castro, 2009). A teoria dos discursos é, nesse sentido, tanto uma tentativa de analisar e de responder a esse conjunto de fenômenos que estão ligados ao processo de reconfiguração do vínculo social quanto de posicionar a psicanálise em relação a ele 5 .

\footnotetext{
3 Consideramos que a crítica do conservadorismo lacaniano não é injustificada. Há, na posição política de Lacan, uma mistura pendular entre tendências conservadoras e subversivas. Por outro lado, a crítica ao lugar que Lacan destina à relação entre psicanálise e ciência é rasa e injusta. Há uma teoria da ciência em Lacan que está longe de ser trivial. Lacan, ademais, num movimento distinto do de Freud, está distante de inserir a psicanálise no ideal da ciência, visto que esta, embora seja considerada a condição para existência da psicanálise, acaba por foracluir o sujeito de sua experiência.

4 Tais críticas podem ser observadas nas passagens abaixo:

"É por isso que sua filha está muda, minhas caras crianças. Ou seja, foi por isso que em maio a coisa esquentou. Foi uma grande tomada da palavra, exprimiu-se alguém que não ocupa um lugar desprezível no meu campo. Tomada da palavra? Creio que seria um erro darmos a essa tomada uma homologia com a tomada de uma Bastilha qualquer. Está mais para uma tragada de cigarro ou de erva, eu diria” (Lacan, 1968-69/2008, p. 41).

"Se tivessem um pouco de paciência, e se aceitassem que nossos improvisos continuassem, eu lhes diria que a aspiração revolucionária somente tem uma chance, a de culminar, sempre, no discurso do mestre. Isto é o que a experiência provou. É o que vocês aspiram como revolucionários, a um mestre. Vocês o terão". (Lacan, 1969-1970/1992, p. 196)

5 A expressão o avesso da psicanálise, que se refere ao discurso do mestre, não é apenas uma crítica ao modo de constituição de vínculos produzido no interior deste mesmo discurso. É, também, uma crítica e uma tentativa de ir um pouco mais além de onde Freud - o mestre da psicanalise pôde ir. Freud, afinal, esteve sob o jugo do ideal da ciência de seu tempo, criou e defendeu a IPA, agindo, por vezes, como um mestre que tentava governar o impossível, e manteve-se fiel ao modelo Edipiano, colocando o Pai no centro de seu sistema. É exatamente contra este Pai que Lacan se insurge e é a partir desta referência que tenta dar um passo adiante.
} 


\section{Os Elementos e os Lugares do Discurso}

Retomemos, após apresentação dessa pequena contextualização histórica, a estrutura dos discursos. Nesta seção, operaremos uma desmontagem dessa estrutura com o objetivo de explicitar cada um dos seus elementos e cada um dos lugares que a constitui.

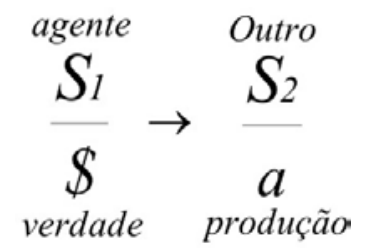

\section{Dos Elementos}

O S1 é o significante-mestre que inscreve a Lei. Ele é ímpar e não dialetizável. Adquire, assim, um poder de comando, de mestria. Trata-se de um comando de repetição, uma vez que sua inscrição "comemora uma irrupção de gozo" (Lacan, 1969-1970/1992, p.73). Esta se refere ao fato de que, ao representar o gozo de uma forma incompleta, o S1 comanda o movimento incessante de se tentar representá-lo novamente.

O S2, por sua vez, representa a cadeia significante que tenta dar sentido ao S1, repetindo-o, mas sempre fracassando. Ele também designa a cadeia de saber que estrutura o inconsciente - um saber que não se sabe.

Como aponta Rabinovich, "o saber tem com o gozo uma articulação peculiar. O ser humano é solidário da insistência de uma escritura, de uma cadeia significante, cuja repetição leva-o além do horizonte homeostático do prazer" (Rabinovich, 2001, p. 6). Gozo e saber (cadeia significante) estão, portanto, intimamente relacionados. O trabalho do inconsciente é instaurado pelo jogo combinatório dos significantes, cuja atividade consiste em uma tentativa de escrever o impossível, a saber: a incapacidade do aparelho psíquico de repetir, como Freud havia já formulado no Projeto, as marcas de prazer da primeira experiência de satisfação [Befriedigungserlebnis].

$\$$ é o sujeito dividido pelo efeito da linguagem. Trata-se de um sujeito barrado, concebido como falta-a-ser. Este sujeito, esvaziado de predicados, é o suporte da experiência do desejo. Ele é cativo dos jogos de representação da cadeia simbólica, sendo o elemento que está representado de um a outro significante desta, a partir de um deslizamento metonímico constante e ininterrupto. Tal como afirma Miller, este sujeito é representado na cadeia significante, embora permaneça sempre, estruturalmente, irrepresentável (Miller, 2012, p. 27). Rabinovich (2001) afirma que:

Este sujeito não pode ser conceituado em termos de organismos nem de necessidades. É sujeito justamente porque essa barra que o divide o faz vir a ser sujeito desejante; desejante de um objeto perdido, proibido, que insiste como objeto do desejo, escapando sempre às redes de $\mathrm{S} 2$, ao mesmo tempo em que as sustenta. Sujeito da ordem simbólica, está para sempre enredado na rede significante. (p. 6)

Por fim, temos o objeto $a$, que pode aparecer de diferentes maneiras de acordo com a sua posição em cada discurso. Como indica Valas (2001):

A teoria dos discursos permite mostrar como o objeto a, que é o núcleo elaborável do gozo, entra em função e que papel ele tem na economia do sujeito. Em cada um dos discursos, ele está em um lugar diferente e, mudando de lugar, ele muda de valor (Valas, 2001, p.76).

O objeto $a$ pode ser pensado ora como causa do desejo, ora como objeto mais-de-gozar. Como causa do desejo, é o objeto perdido na operação de inscrição da lei simbólica [castração]. Nesse sentido, representa a falta no Outro, e, como tal, é o que impulsiona o sujeito no movimento infinito de seu desejo.

Como mais-de-gozar, o objeto $a$ refere-se à experiência de um gozo perdido que o sujeito trata de tentar recuperar, por isso sua vinculação à repetição, ao caráter parcial da satisfação pulsional e à dimensão entrópica da pulsão de morte. O objeto $a$ sintetiza um paradoxo: trata-se do elemento que expressa a perda derivada da entrada do sujeito na estrutura da linguagem, ao mesmo tempo em que o impulsiona a recuperar o impossível. Portanto, ele indica um gozo a menos, produto inexorável da própria existência da estrutura, enquanto produz um excedente, um a-mais: a repetição como meio e tentativa de obter o impossível: 
é apenas nesse efeito de entropia, nesse desperdiçamento, que o gozo se apresenta, adquire um status. Eis porque o introduzi de início com o termo Mehrlust, mais-de-gozar. É justamente por ser apreendido na dimensão da perda - alguma coisa é necessária para compensar, por assim dizer, aquilo que de início é um número negativo - que esse não-sei-quê, que veio bater, ressoar nas paredes do sino, fez gozo, e gozo a repetir. Só a dimensão da entropia dá corpo ao seguinte - há um mais-de-gozar a recuperar (Lacan, 1969-1970/1992, p.47-48).

\section{Dos Lugares}

O agente do discurso está localizado acima da barra e à esquerda. Na estrutura, a barra indica o que está recalcado no discurso, a saber: a sua verdade. $\mathrm{O}$ agente é quem aparentemente domina o discurso e é quem dá nome a ele. Essa aparência ou semblante de domínio está relacionada a um engodo, visto que, da sua posição, ele normalmente desconhece a verdade que o atravessa. abaixo:

$\mathrm{O}$ agente, porque está no lugar de dominância, determina a intencionalidade do discurso, tal como pode ser visto logo

1. Discurso do mestre / Ato $\rightarrow$ governar / A Dominante é a Lei (S1);

2. Discurso da histérica / Ato $\rightarrow$ fazer desejar / A Dominante é o sintoma (\$)

3. Discurso da universidade / Ato $\rightarrow$ educar / A Dominante é o saber (S2);

4. Discurso do analista / A to $\rightarrow$ analisar / A Dominante é o rechaço à posição do mestre (Objeto $a$ pensado como causa de desejo).

O Outro, por sua vez, está localizado acima da barra e à direita. Lacan o define como a referência de um discurso, ou seja, "aquilo que ele [o discurso] confessa querer dominar, querer amestrar" (Lacan, 1969-1970/1992, p.65). O lugar do Outro é, portanto, o lugar do dominado.

A seta que vai do agente em direção ao Outro deve ser entendida como o poder de dominação, revelando que, em todo discurso, mesmo no do analista, ele [o poder] é exercido. É verdade que Lacan insere, junto a essa seta, a demarcação de um ponto de impossibilidade, o que significa, na sua notação, a existência, em cada um dos discursos, de um ponto real, que age como um limite ao alcance da própria estratégia de dominação utilizada.

O Outro, se seguirmos a ordem dessa apresentação dos lugares, deverá sempre produzir ou perder algo. Ora, esse lugar - o da produção - encontra-se, na estrutura discursiva, situado abaixo e à direita e indica o produto de cada discurso ou o seu resto. Fizemos, logo abaixo, uma rápida síntese do que os quatro discursos engendram:

1. Discurso do mestre $\rightarrow$ o outro (o escravo) deve produzir objetos de gozo para o mestre.

2. Discurso da histérica $\rightarrow$ o outro (o mestre) deve produzir um saber sobre o desejo da histérica.

3. Discurso da universidade $>$ o outro (a-estudante) deve produzir sua própria divisão, ou seja, o reconhecimento de sua própria falta de saber.

4. Discurso do analista $>$ o outro (sujeito) deve produzir [ou deixar cair] o significante-mestre que estrutura seu sintoma.

Por fim, há o posto da verdade, localizado, nesta estrutura quadrangular, embaixo e à esquerda. A verdade é o fundamento recalcado de cada um dos discursos. Não se pode dizê-la toda, visto que seu acesso só é possível por meio de um semidizer. Esta impossibilidade é grafada nos matemas por uma barra de disjunção, que separa o produto da verdade. Tal impotência está em grande medida relacionada ao ponto de opacidade do sexual, isto é, ao reconhecimento da inexistência de uma proporção natural entre os sexos, proporcionado pela experiência psicanalítica. $\mathrm{O}$ encontro dos sexos é, nesse sentido, o que não cessa de não se escrever.

Uma vez apresentados os quatro elementos e os quatro lugares, podemos, agora, avaliar com um pouco mais de precisão como funciona cada um dos quatro discursos. 


\section{O Discurso do Mestre}



Para compreendermos o que está em questão no discurso do mestre, é necessário, porque Lacan o extrai daí, compreendermos o modo como se dá, para Hegel, a relação dialética entre o senhor e o escravo, descrita no capítulo 4 da Fenomenologia do Espírito (Hegel, 1808/1992) ${ }^{6}$.

A Dialética do senhor do escravo pode ser considerada como "uma matriz fenomenológica geral", que confere inteligibilidade a processos empíricos de socialização observados em núcleos elementares de interação social, tais como a família, a sociedade civil, as instituições, o Estado, etc. (Safatle, 2006, p. 9-10). Trata-se, se nos for permitido utilizar o vocabulário lacaniano, de uma descrição das intrincadas relações de identificação, alienação e separação, que determinam as vicissitudes das relações intersubjetivas percebidas durante o processo de constituição do sujeito (Souza, 2015).

Resumindo-a de modo bastante condensado, podemos dizer que o solo ontológico da formação da consciência-de-si descrita na Dialética é, em Hegel, destacadamente conflituoso, já que todo o processo é propulsionado por uma falta que opera no nível de um desejo de reconhecimento dirigido a outra consciência que, especularmente, deseja a mesma coisa.

Este encontro entre ambas dará origem a uma batalha em que o ser da consciência só é atestado e obtido por intermédio do reconhecimento de uma consciência que lhe é estrangeira. Ser-para-si significa, de igual modo, ao menos nesse instante, ser-para-o-Outro. Desse conflito, ou dessa batalha de puro prestígio - como a nomeia Kojève -, cujo horizonte é a confrontação com a morte, o saldo final é o recuo de uma das consciências.

Esse recuo diante da morte, necessário para que a dialética do reconhecimento se mantenha, provoca uma cisão entre as partes, e estabelece a determinação de duas posições finitas e antagônicas: por um lado, surge uma consciência independente para o qual o ser-para-si é a essência; por outro lado, surge uma consciência dependente, que retrocedeu diante da morte e para quem seu ser consiste em ser para um Outro. "Uma é o senhor [S1], outra é o escravo [S2]" (Hegel, 1808/1992, 130).

A partir de então, o senhor e o escravo passam a se relacionar por intermédio das coisas que o último produz [a]. A relação do mestre com essas coisas não pode ser definida somente mediante a posse, o gozo e o consumo, uma vez que isso implicaria a destruição do objeto sem, contudo, efetivar a realização do seu desejo de reconhecimento. A satisfação do desejo só ocorre se o objeto consumido duplicar a estrutura da consciência, ou seja, se sua posse for, em igual medida, a posse e o gozo do que o escravo produz e deseja. A argúcia do senhor consiste em colocar o escravo entre ele e a coisa. Como o escravo é quem produz e estima os objetos que entrega ao senhor, poder (de vez em quando) gozar da posse de alguns deles torna-se o seu maior sonho, visto que é esse o modo mais direto de avizinhar-se da potência de seu amo.

Hegel, contudo, aponta que esse não é final da relação dialética. Ela passaria, ao contrário, na sua fase derradeira, pelo reconhecimento do escravo de que é ele quem detém todo o saber da produção. Bastaria que fizesse greve para que o senhor descobrisse sua subalternidade (\$), ou seja, sua divisão e sua verdadeira dependência da outra consciência. Ao compreender a sua própria potência, o escravo daria o passo final da dialética, que consistiria em suprassumir o seu ser como ser para si (Souza, 2015).

Lacan (1969-1970/1992), ao analisar essa relação dialética, critica a posição utópica de Hegel. Como todo discurso está marcado por um ponto de impossibilidade, não é nem no sucesso do comando, nem no sucesso da superação dialética, que devemos compreendê-lo. Ao contrário, é onde esse discurso fracassa, onde ele não funciona, onde ele se repete, que devemos buscar sua razão. Lacan dirá, dessa maneira, que o escravo [S2], que é quem detém o saber da

6 O hegelianismo lacaniano, é importante afirmar, não é direto. Ele, pelo contrário, é derivado de sua frequentação aos seminários sobre a Fenomenologia do Espírito, ministrados por Alexandre Kojève, durante a década de 1930, em Paris. Ora, sabe-se que Kojève se utilizou de um método de leitura bastante inventivo, mas que, dificilmente, poderia ser sustentado como comentário sistemático do texto (Safatle, 2006, p, 43).

Kojève converteu o sistema hegeliano em uma antropologia filosófica, fato que, ademais, foi determinante para a constituição daquilo que ele nomeou como ontologia dualista. A antropologização do texto hegeliano acabou por levar Kojève a um afastamento da filosofia da natureza de Hegel. (Safatle, 2006, p. 27).

Para maior esclarecimento sobre esta questão, que não terá impacto maior sobre o curso de nossa argumentação, ver: Arantes, P. E. (1992). Hegel no espelho do Dr. Lacan. IDE, n.22, p. 64-77. 
produção, ao trabalhar para o Senhor [S1], goza [a] do lugar que ocupa. "O discurso do mestre nos mostra o gozo como vindo ao Outro - é ele que tem os meios" (Lacan, (1969-1970/1992).

O trabalho, diz-nos ele [Hegel] a que se submete o escravo, renunciando ao gozo por meio da morte, será justamente a via pela qual ele realizará a liberdade. Não há engodo mais manifesto politicamente e, ao mesmo tempo, psicologicamente. O gozo é fácil para o escravo e deixará o trabalho na servidão (Lacan, 1960/1998, p. 825).

Lacan afirma, portanto, que o que mantém a servidão, impedindo a assunção da sua liberdade, é o gozo usufruído pelo servo por sua própria condição de escravidão.

Tal conclusão, embora pareça muito radical, sobretudo para aqueles que alimentam um forte ideal de liberdade, não deixa de ser verificada cotidianamente em nossa história. Essa fixação à posição servil não aparece apenas entre os neuróticos obsessivos, ou seja, entre aqueles que gozam do sacrifício que fazem da própria vida quando obedecem à voz imperativa e intransigente do supereu. Ela também se revela nas experiências filosófica, religiosa e política. Entre as últimas, particularmente, temos visto, na atualidade, tanto o triunfo de religiões enrijecidas e passionais, que atraem cada vez mais adeptos pelo mundo, quanto o ressurgimento das políticas autocráticas, concentradas em figuras que se apresentam como salvadoras e que arrastam multidões.

\section{O Discurso Universitário}

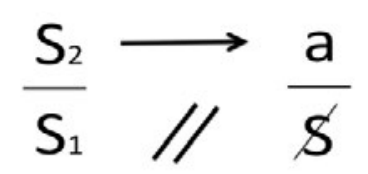

O matema desse discurso revela que quem o agencia é o saber. Este saber, saber do universitário, é o mesmo saber do especialista que, na academia, tal como observamos com força cada vez maior, é validado e paramentado a partir do longo conjunto de títulos de seu portador.

Lacan propõe que esse é o discurso da burocratização da vida, na medida em que a burocracia pode ser pensada como um aparato técnico-administrativo, baseado em um método que é responsável por definir parâmetros racionais, capazes de ordenar, regular e avaliar o funcionamento de um sistema ou de uma instituição. O objetivo não é apenas manter as coisas em ordem, mas manter uma ordem que funcione bem. Funcionar bem quer dizer, ao menos dentro de uma lógica utilitarista, maximizar a produção e a utilidade, de tal modo que possamos produzir mais, melhor e para um maior número possível (Souza, 2015).

Muito embora o que dê nome ao discurso nos convide a pensar sobre o modo como se estrutura a produção de saber no interior dos muros acadêmicos, a adesividade a ele está para muito além desse lugar circunscrito. A universidade é apenas um modelo limitado de um conjunto bem mais extenso e amplo. Na verdade, esse discurso se apresenta como uma síntese do modo como o saber circula no laço social contemporâneo.

A leitura do nível superior da fórmula [S2 $\rightarrow$ a] mostra que o saber [S2] que agencia o discurso dirige-se para o objeto que ocupa o posto do Outro. É possível afirmar que esse saber - que se empenha no esforço de domínio, integração, domesticação e apropriação do objeto - , encontra na sua trajetória, todavia, um elemento que lhe impõe certa resistência $[a]$. A característica mais típica desse objeto é a rejeição em deixar-se apreender ou totalizar pelos procedimentos seguros de objetividade e de objetificação. Não é sem razão que, dessa tentativa de sua completa absorção ao domínio do saber, resulte, como produto, um sujeito dividido [\$] (Souza, 2015).

Zizek (2012) diz que o discurso universitário se estrutura em torno do ideal do totalitarismo burocrático. Ele se apresenta "sob diferentes disfarces, como o papel da tecnologia, da razão instrumental, da biopolítica", enfim, de toda essa base ideológica da organização e da administração total da vida. Ele opera por meio da vigilância e da regulação paroxística de processos e sistemas. Não seria demais pensar que sua estratégia gerencial, que tem como fim atingir o ideal da seguridade plena, realizar-se-ia por meio da construção do panóptico (Jeremy Bentham). Essa máquina de vigiar ideal faria tremular a flâmula do controle máximo. Talvez por isso que o trabalho ininterrupto do especialista seja requisitado com tanta intensidade. É necessário e urgente que ele conheça, domine, controle e produza para, por um lado, permitir que a cultura da organização completa advenha e que, por outro lado, nada, absolutamente nada, saia de ordem 7 .

$\overline{7}$ Ver, sobretudo, Agamben (2014). Como a obsessão por segurança muda a história da democracia. Link 


\section{O Discurso do Analista}



Neste discurso, temos, no lugar do agente, o analista $[a]$, que aqui se faz de semblant de objeto causa de desejo:

Em se tratando da posição dita do analista, ... é o próprio objeto $a$ que vem no lugar do mandamento. É como idêntico ao objeto $a$, quer dizer, a isso que se apresenta ao sujeito como a causa do desejo, que o analista se oferece como ponto de mira para essa operação insensata, uma psicanálise, na medida em que ela envereda pelos rastros do desejo de saber (Lacan, 1969-1970/1992, p.99).

Por apontar o discurso do mestre como seu avesso, esse discurso demonstra mais claramente a impossibilidade do ato de governar: "ao se fazer de objeto causa do desejo, o psicanalista lança o sujeito na sua divisão, demonstrando-lhe isto: que o inconsciente [o desejo] não se deixa dominar" (Bispo \& Souza, 2013, p. 641). A análise revela exatamente aquilo que o seu avesso esconde.

A relação estabelecida nesse discurso é muito particular, pois é o único, dentre os quatro, que propõe um enlaçamento com o sujeito [\$] e que reconhece tanto a impossibilidade de dominá-lo quanto a impossibilidade da consumação do vínculo fantasmático [a $\diamond \$$ ], que, na álgebra lacaniana, estaria ligada ao tamponamento da falta do Outro [A/].

O saber [S2], que aqui se encontra no lugar da verdade, não é outro senão aquele ocupado pela intepretação ou, ainda mais radicalmente, pela dimensão do ato analítico. Como tal, ele não visa à totalização do sentido por meio da crença em uma decifração completa do saber recalcado, que teria como efeito ampliar o escopo de abrangência da consciência (tornar todo o real racional). Ao contrário, tende a revelar a impotência do significante diante do real, ou seja, tende a tocar naquilo que há de impossível no domínio da relação entre os sexos.

Esse discurso, enfim, produz como resto o significante mestre [S1], isto é, aquele traço mais primitivo - o unário - que, excluído da cadeia, lançou o sujeito na direção da norma fálica, vinculando-o ao campo articulado do Outro. A queda desse significante implica no atravessamento de uma posição fixa de gozo, engendrando como saldo positivo no final de uma análise a abertura para o acolhimento de uma experiência radical de indeterminação (Souza, 2015).

O discurso do analista é, portanto, fundado na ética do desejo. Como tal, ele reconhece não apenas sua dimensão inconsciente, como também "permite circunscrever o real de que sua impossibilidade exerce a função" (Lacan, 1970/2003, p. 446). Esse discurso não nega o impossível, mas leva o sujeito a percorrer sua impotência frente ao Outro até acuá-lo em seu último reduto. Nesse ponto, "ele descobre que, no final das contas, o Outro não existe, isto é, não há um lugar de onde alguém poderia suprir a sua falta" (Bispo \& Souza, 2013, p. 642). Afinal, o objeto que o analisante procura não pode, por uma impossibilidade engendrada pela própria existência da estrutura, ser encontrado.

\section{O Discurso da Histérica}

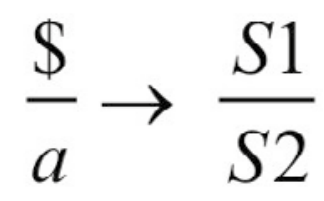

O discurso da histérica, enfim, tem um lugar privilegiado na história da psicanálise. Segundo Rabinovich (2001), é o discurso que funda esse campo que se ocupa daquilo que escapa ao discurso tradicional. Quando Freud se deparou com as histéricas que desafiavam os saberes médicos de sua época, foi convocado a produzir um saber inédito, um saber sobre o inconsciente. Essa forma de vínculo social provoca a produção do saber. É o laço daqueles que buscam respostas no Outro.

Nesse discurso, a histérica aparece como um sujeito [\$] que, alienado da verdade sobre seu gozo $[a]$, se dirige ao mestre [S1], pressionando-o para que produza um saber sobre sua condição. Os saberes produzidos pelo mestre são, um a um, descartados, uma vez que não dão conta, ou suprem apenas parcialmente, aquilo que concerne à sua verdade. O mestre, que a princípio parecia revestido de uma potência soberana, tem, afinal, revelada a sua verdade: ele é castrado. O que a histérica deseja é justamente isto: "um mestre sobre o qual ela reine. Ela reina e ele não governa" (Lacan, 1969-1970/1992, p. 122). 
Embora a histérica coloque o mestre em movimento, fazendo-o produzir sempre um saber a mais sobre sua condição, o que ela mantém recalcado, e é o ponto contra o qual todo o saber se revela impotente, é o enigma da sua própria feminilidade. Afinal, o que quer uma mulher?

\section{Conclusão}

Buscamos com este trabalho propor uma revisão da teoria lacaniana dos discursos seguindo, para tanto, três diferentes vias: primeiro, propusemos uma definição do que se deve compreender como discurso e como essa teoria é estabelecida a partir de uma revisão do estruturalismo, motivada pela inserção do objeto $a$ na teoria, pensado, agora, pela vertente do mais-de-gozar. Em seguida, situamos a teoria dos discursos no universo da obra lacaniana, tanto apontando para o contexto histórico que a motivou quanto indicando a ruptura interna que ela provocou com a teoria freudiana, que, como é sabido, se sustenta no complexo de Édipo e tem na figura do Pai seu lugar de ancoragem. Por fim, fizemos uma desmontagem dos discursos, objetivando conceituar seus elementos e definir seus lugares, para, na sequência, avaliar o que cada um produz do ponto de vista das formas de enlaçamento social. Destacamos, nesse último percurso, os pontos de impossibilidade dos discursos, indicando os modos que eles, prevalentemente, utilizam ou para rejeitá-lo e/ou para reconhecê-lo.

\section{Referências}

Agamben, G. (2014). Como a obsessão por segurança muda a história da democracia. Le monde diplomatique Brasil. Link Arantes, P. E. (1992). Hegel no espelho do Dr. Lacan. IDE, 22, 64-77.

Bispo, F. S, \& Souza, M. F. G (2013). O discurso psicanalítico entre outros: Considerações sobre Radiofonia. Revista Estudo e pesquisa em psicologia, 13(2), 625-645.

Castro, J. E. (2009). Considerações sobre a escrita lacaniana dos discursos. Revista Ágora, 13(2), 245-258.

Deleuze, G. (1974). Em que se pode reconhecer o estruturalismo. In F. Châtelet, História da Filosofia: ideias, doutrinas: O séc. XX (Vol. 8, pp. 239-269). Rio de Janeiro: Jorge Zahar.

Hegel, K. W. F. (1992). Fenomenologia do espirito, parte I (P. Meneses, Trad.). Petrópolis: Vozes. (Originalmente publicado em 1808)

Lacan, J. (1992). O seminário, livro 17: O avesso da psicanálise. Rio de Janeiro: Jorge Zahar. (Originalmente publicado em 1969-1970)

Lacan, J. (1998). Subversão do sujeito e dialética do desejo. In J. Lacan, Escritos (pp. 807-842). Rio de Janeiro: Jorge Zahar. (Conferência pronunciada em 1960)

Lacan, J. (2003). Radiofonia. In J. Lacan, Outros escritos (pp.400-447). Rio de Janeiro: Jorge Zahar. (Originalmente publicado em 1970)

Lacan, J. (2008). O seminário, livro 16: De um Outro ao outro. Rio de Janeiro: Jorge Zahar. (Originalmente publicado em 1968-1969)

Miller, J. A. (2012). Os seis paradigmas do gozo. Opção Lacaniana, 3(7), 1-49. Link

Rabinovich, D. (2001). O Psicanalista entre o Mestre e o Pedagogo. Cadernos de Psicologia, 11(1), 9-28.

Safatle, V. (2006). A paixão do negativo: Lacan e a dialética. São Paulo: Editora UNESP.

Souza, M. (2015). O Nome-do-Pai em Jacques Lacan: Declinações e negatividade (Tese de doutorado. Programa de Pós- 
graduação em Psicologia), Universidade Federal de Minas Gerais, MG.

Valas, P. (2001). As dimensões do gozo: Do mito da pulsão à deriva do gozo (L. Magalhães, Trad.). Rio de Janeiro: Jorge Zahar. (Originalmente publicado em 1998)

Thiollent, M. (1998). Maio de 1968 em Paris: Testemunho de um estudante. Tempo Social, 10 (2), 63-100.

Zizek, S. (2012). Os quatro discursos de Jacques Lacan (R. N. L. Pereira, trad.). Link

\section{Endereço para correspondência}

Luis Flávio Silva Couto

Email: luisflaviocouto@terra.com.br

Jônatas Lança de Queiroz Casséte

Email: jonataslqc@hotmail.com

Fernando Hartmann

Email: fernandohartmann37@gmail.com

Marcelo Fonseca Gomes de Souza

Email: marcelofgsouza@gmail.com 